\title{
Amyloid-like aggregates formation by bovine apo-carbonic anhydrase in various alcohols: a comparative study
}

Ali Es-haghi ${ }^{*}$, Azadeh Ebrahim-Habibib, Marjan Sabbaghianc ${ }^{c}$, Mohsen Nemat-Gorgani, ${ }^{d}$

a. Department of Biology, Mashhad Branch, Islamic Azad University, Mashhad, Iran

b. Biosensor Research Center, Endocrinology and Metabolism Molecular-Cellular Sciences Institute, Tehran University of Medical Sciences, Tehran, Iran

c. Department of Andrology at Reproductive Biomedicine Research Center Royan Institute for Reproductive Biomedicine, ACECR, Tehran, Iran

d. Stanford Genome Technology Center, Stanford University, Palo Alto, CA, USA

e. Corresponding author: Faculty of science, Department of biology, Islamic Azad university, Mashhad Branch, Mashhad, Iran TEL :+98 38435050 E-mail address: ashaghi@gmail.com (Ali Es-haghi)

\section{Abbreviations:}

BCA II, bovine carbonic anhydrase II; PMG, pre-molten globule; MG, molten globule; ThT, thioflavin T; CD, circular dichroism; AFM, atomic force microscopy; ANS, 1-anilinonaphthalene 8-sulfonate; DLS, dynamic light scattering; TFE, 2,2,2-trifluoroethanol; HFIP, 1,1,1,3,3,3-hexafluoroisopropanol; 


\begin{abstract}
Peptides and proteins convert from their native states to amyloid fibrillar aggregates in a number of pathological conditions. Characterizing these species could provide useful information on their pathogenicity and the key factors involved in their generation.
\end{abstract}

In this study, we have observed the ability of the model protein apo-bovine carbonic anhydrase (apo-BCA) to form amyloid-like aggregates in the presence of halogenated and non-halogenated alcohols. Far-UV circular dichroism, ThT fluorescence, atomic force microscopy and dynamic light scattering were used to characterize these structures. The concentration required for effective protein aggregation varied between the solvents, with non-halogenated alcohols acting in a wider range. These aggregates show amyloid-like structures as determined by specific techniques used for characterizing amyloid structures. Oligomers were obtained with various size distributions, but fibrillar structures were not observed. Use of halogenated alcohols resulted into smaller hydrodynamic radii, and most stable oligomers were formed in hexafluoropropan-2-ol (HFIP). At optimal concentrations used to generate these structures, the non-halogenated alcohols showed higher hydrophobicity, which may be related to the lower stability of the generated oligomers. These oligomers have the potential to be used as models in the search for effective treatments in proteinopathies.

Keywords: Carbonic anhydrase, Metalloprotein, Pre-molten globule, Alcohol, HFIP 


\section{Introduction}

Alcohols affect proteins and peptides native conformations, may induce helices, dissolve peptide aggregates, or be used as co-solvents to induce fibrillar structures [1]. Amyloid fibrils occupy an important place in the pathophysiology of several diseases such as Alzheimer's disease, dialysis-related amyloidosis, and type II diabetes mellitus [2]. In addition, a number of proteins and peptides have been observed to form similar fibrillar deposits in vitro, even though not related to any pathology [3]. Numerous studies have been conducted on these biologically important protein forms, but the fine details of fibril formation mechanism are still not elucidated [4]. For Most proteins, fibril formation will initiate under denaturing conditions [5], provided by a variety of conditions, including halogenated alcohols [6].

We have used carbonic anhydrase as a model protein to address the lack of a comprehensive study on various alcohols in a similar setting. Carbonic anhydrase II (CA, EC 4.2.1.1) is a globular protein of 259 amino acids with a molecular weight of 30 $\mathrm{kD}$. Found in red blood cells, this enzyme is normally present as a monomer with a zinc atom in the active site. The bovine enzyme is composed of $10 \beta$-strands and a small amount of $\alpha$-helices [7] [8]. At low pH, the apo form of bovine carbonic anhydrase (apoBCA) unfolds via an apparent four-state process, comprising molten and pre-molten globule species [9]. Apo-BCA molten globule tends to form amorphous aggregates when incubated at high temperature, while pre-molten globule is able to convert to amyloid fibrils. Surface hydrophobicity and conformation of the starting structures are likely to play important roles in the obtained aggregates characteristics [10]. 
Here, we have compared the amyloid-like structures formed by apo-BCA in the presence of various concentrations of halogenated (TFE, HFIP) and non-halogenated (methanol, ethanol, propanol) alcohols, using CD spectroscopy, ThT fluorescence and atomic force microscopy (AFM). In the absence of alcohol and at low $\mathrm{pH}$, apo-BCA takes the pre-molten globule form [11]. Addition of alcohols to the protein causes its aggregation, and these aggregates are capable to bind specific amyloid-reporting molecules. To binding to these compounds (ThT and Congo red), extensive $\beta$ sheet structures should be present in the protein, and these are characteristic of amyloid structures [12]. These species may be related with the protein and peptide states involved in the "protein deposition diseases" and could be useful for cell toxicity assays and for modeling pathogenic states of the actual disease-linked proteins.

\section{Results and discussion}

\subsection{Detection of structural changes by ThT fluorescence and CD spectra}

Effects of buffer type, ionic strength, solution $\mathrm{pH}$, and different concentrations of the protein have been previously investigated on amyloid or amyloid-like formation [10]. Only when the protein is incubated at $\mathrm{pH} 2.4$, and takes a pre-molten globule state, is it able to move toward amyloid formation. At $\mathrm{pH} 3.5$, in which the protein has a molten globule structure [13], amyloid formation is not observed. This indicates the importance of both structure flexibility and hydrophobicity in the polymerization process [14]. 
Here, purified protein $\mathbf{1 3 3} \boldsymbol{\mu} \mathbf{M}$ was incubated in a $\mathbf{5 0 m M}$ Glycine buffer $(\mathrm{pH} 2.4)$, at room temperature, and in the presence of various concentrations of alcohols for 24 hours. ThT assay was performed, which is a widely used technique to detect amyloid aggregates, and based on fluorescence emission at $485 \mathrm{~nm}$. As shown in Fig.1, sharp increases in emission intensity were observed in different ranges of alcohol concentrations. Accordingly, far UV-CD spectra of these samples showed conformational changes of the protein which indicates the presence of $\beta$-structure in the aggregates. $\mathrm{CD}$ spectrum of Apo-BCA at pH 2.4 has a minimum at $200 \mathrm{~nm}$, which shows the presence of the pre-molten globule structure [11], and appearance of a negative peak at about $215 \mathrm{~nm}$ in far- CD spectrum is taken as the sign of beta-amyloidtype structure formation [15]. The term "amyloid-like" has been previously used for designing stable oligomeric structures which could be detected with amyloidspecific methods, but do not form the distinct fibrils that are characteristic of "amyloids" [16-18].

These results show suitable concentrations of the tested alcohols for amyloid-like aggregates formation of apo-BCA. For non-halogenated-alcohols, as an increase occurs in carbon chain length, a higher concentration is required for amyloid-like aggregate formation. Optimal concentration for methanol to form amyloid-like aggregates was $35 \%(\mathrm{v} / \mathrm{v})$, while in the case of ethanol a 20 to $60 \%(\mathrm{v} / \mathrm{v})$ concentration range resulted in amyloid-like aggregates and the optimal concentration (i.e. concentration needed for maximum aggregation) was 45\%. For 1 - propanol, aggregates were formed in the range of $40 \%$ to $60 \%(\mathrm{v} / \mathrm{v})$, and the optimal concentration was $60 \%(\mathrm{v} / \mathrm{v})$. At higher concentration of propanol (above 65\%), the 
protein was precipitated. Similar results were obtained for isopropanol, indicating that the position of the hydroxyl group has no effect on the aggregation process.

For halogenated alcohols, the process was different and only a small range of alcohol concentrations resulted in formation of amyloid-like structures. The optimal concentration to form amyloid-like aggregates was $12 \%$ and $5 \%$ for TFE and HFIP, respectively. The effect of HFIP is significantly different from other alcohols, because at high concentrations (greater than $50 \%$ to $70 \%$ ), it can induce alpha-helix in protein, which requires a large structural rearrangement. In the literature, this abnormal protein a-helix is described as an "open helical state" [19]. At high concentrations of HFIP, the hydrophobicity of the solution is high and may stabilize the monomeric state of $\alpha$-helical proteins, inhibiting amyloid-like aggregate formation [20]. In a recent study, it has also been reported that at high concentrations of TFE, alpha helix structures are detected in human carbonic anhydrase [21].

Electrostatic and hydrophobic interactions are both involved in the process. Low polarity of a solvent results in decreased strength of hydrophobic interactions (crucial in protein structural integrity) when at the same time, local hydrogen bonds are reinforced [22]. More hydrophobic alcohols with longer chain may thus exert their effects at higher concentration (e.g. propanol versus methanol).

On the other hand, dielectric constant decreases in organic solvents. Dielectric constant of TFE is 27, while that of water is 78; [23] consequently, enhanced electrostatic interactions, including polar interactions and charge-charge interaction, may occur in water-alcohol mixtures [24, 25]. At low concentrations of HFIP, hydrophobic and electrostatic interactions are enhanced [26]. In HFIP and TFE, dynamics clusters are 
formed, to a higher extent compared with other alcohols [27, 28]. Protein interaction with these dynamic clusters may increase the overall hydrophobicity, leading to aggregation [29]. This may explain why a particular concentration of HFIP and TFE are required to form amyloid-like structures.

\subsection{Aggregates morphology observed with Atomic force microscope (AFM)}

Structures formed under optimal concentrations of each alcohol were probed with the use of atomic force microscopy. Figure 2 shows the images obtained for apo-BCA after $24 \mathrm{~h}$ of incubation in each optimal concentration of the alcohols. The observed aggregates possess regular structures since they bind to ThT and the CD spectra show that they contain large amounts of $\beta$ - structure (Fig.1), but mature fibrils were not formed. The height of each oligomer was analyzed by WSxM software, and results of statistical analysis shown in Table 1. Oligomers generated in HFIP and ethanol have uniform heights, while in other alcohols heterogeneity is observed. In HFIP, species with $2.02 \pm 0.495 \mathrm{~nm}$ in height were generated while oligomers formed in $12 \%$ TFE had three different heights of $2.9 \pm 0.600,7.2 \pm 1.01 \mathrm{~nm}$, and $11.1 \pm 1.195 \mathrm{~nm}$. Two different heights of oligomers were also detected in $35 \%$ methanol as $8.5 \pm 1.092$ and $12.9 \pm 1.77 \mathrm{~nm}$. In ethanol, only particles with heights of $5.23 \pm 0.705$, and in propanol two particles population with heights of $7.46 \pm 0.664$ and $10.28 \pm 1.104$ were formed. Maximal heights of oligomers formed in fluroalcohols are thus slightly less than oligomers produced in non- halogenated alcohols (Table 1). 
In summary, based on AFM images, high amounts of large aggregates with various heights have been obtained in various alcohols with amyloid-like properties and high $\beta$ structure contents.

Similarly, stable oligomers have been observed for the Hypf-N protein in the presence of TFE and under alkaline conditions, and fibrillar structures were not detected [16]. It has also been reported that the net charge of ovalbumin affects the nature of intermolecular interactions as well as the final aggregates structure [30]. Fibrillar structures are formed when hydrophobic and polar interactions are optimal. Although a linear correlation may be assumed between electrostatic interactions and alcohol concentration, for fibril formation, hydrophobic interactions must also be optimized. It is in the absence of such optimal hydrophobic interactions that regular beta containing structures may still form but fibrils will not be obtained [17, 31].

\subsection{Hydrodynamic radii of amyloid-like aggregates (DLS)}

Size evaluation of apo-BCA aggregates was further made by a DLS analysis. As shown in Figure 3, two types of oligomeric amyloid-like aggregates with different hydrodynamic radii were formed in each alcohol. Particles formed in methanol have diameters of about $26 \mathrm{~nm}$ and $70 \mathrm{~nm}$, while for ethanol $26 \mathrm{~nm}$ and $143 \mathrm{~nm}$, for propanol $40 \mathrm{~nm}$ and $123 \mathrm{~nm}$, for TFE $19 \mathrm{~nm}$ and $49 \mathrm{~nm}$, and for HFIP $25 \mathrm{~nm}$ and $100 \mathrm{~nm}$ were detected. The effective diameter for non-halogenated alcohols increases with increasing length of the carbon chain, as oligomers generated in 1- propanol show higher hydrodynamic effective diameter compared with those generated in other alcohols. On the other hand, the hydrodynamic radii of oligomers formed in fluroalcohols are smaller. 


\subsection{Kinetics of amyloid-like formation in the presence of TFE}

To identify the kinetics and the conformational change of apo-BCA amyloid-like formation, CD-spectra changes were monitored in the presence of TFE. CDspectroscopy was chosen over ThT fluorescence, since it is better suited with this regard.

Amyloid-like aggregates formation starts without nucleation. In Figure 4, it is clear that as soon as TFE is added, the protein takes a new conformation which is different from pre-molten globule structure and closer to alpha-helix, because in far-UV CD, the 200 $\mathrm{nm}$ peak shifted to $207 \mathrm{~nm}$ and peak depth of $222 \mathrm{~nm}$ increased. This structure is known as an alpha-helix intermediate structure. The protein spends about 15 minutes in this intermediate conformation. After about 30 minutes, this intermediate structure is converted to beta structure- containing aggregates. A number of studies have reported that for amyloid formation to occur, an a-helical intermediate is necessary [32, 33]. As examples, HIAPP peptide incubated in 10\% HFIP $(\mathrm{v} / \mathrm{v})$ in acidic conditions and Barstar protein incubated in HFIP and TFE take alpha helical structures [34]. The originally unstructured a-synuclein has also been observed to form two alpha-helical intermediates at low concentrations of fluoroalcohols [35]. On the other hand, as previously mentioned, high concentration of HFIP induces an open helical state in CA. Clusters and micelle-like structures would disappear at higher concentrations of alcohols, while the alpha-helical conformation may still be present. High hydrophobicity would stabilize the monomeric alpha-helical state, and prevent amyloid or amyloid-like formation [29]. Further studies are required to 
investigate the importance or generality of alpha-helix intermediates in amyloid or amyloid-like aggregates formation. It is interesting that the alpha-helix intermediate structure is able to bind to ThT, but the mechanism is still not elucidated. Recent reports show that ThT binds to the structures which are rich in aromatic amino acids [36].

\subsection{Hydrophobicity and stability of oligomers}

ANS emission was used as a marker in order to evaluate surface hydrophobicity of oligomers generated in alcohols. Figure 5 shows ANS fluorescence emission in each concentration of various alcohols where after 24 hours, emission intensity was measured and plotted against alcohol concentration. Emission intensity increased with increasing alcohol concentration up to an optimal level, which is taken as the best condition for amyloid-like formation. The similar trend of ANS emission change in alcohols is indicative of a concordance between optimal concentration of alcohols and highest surface hydrophobicity. This means that the amyloid-like oligomers formed in various alcohols are all highly hydrophobic. In the concentrations of alcohols where amyloid-like formation has not occurred, but high ANS intensity is still observed, other structural changes should have happened; in fact at all alcohol concentrations, ANS emission is higher compared with the emission detected for the monomeric pre-molten globule.

Stability of oligomers formed in the presence of optimal concentrations of alcohols was checked by ThT emission intensity over time. Figure 6 indicates that the oligomeric forms created in halogenated alcohols show significantly higher stability than those formed in the non-halogenated alcohols. Of these, the oligomers formed in 
HFIP were very stable, so that after 24 hours, about $15 \%$ of the emission intensity of ThT decreased, while for oligomers formed in TFE, about $30 \%$ and for other oligomers of non-halogenated alcohols over $50 \%$ of ThT emission intensity was diminished at the same time. This would imply that the intermolecular interactions involved in the formation of these aggregates are stronger in halogenated alcohols compared with those initiated in other alcohols. A plausible explanation for such behavior may be the differences in alcohols hydrophobicity.

Accordingly, hydrophobicity of the environments used to generate amyloid-like structure was determined using ANS fluorescence. The results show different hydrophobicity of alcohols, and the fact that with increasing alcohol concentration, increase of hydrophobicity occurs (as interpreted from increase in ANS emission).

Figure 7 indicates that solutions of non-halogenated alcohols have a higher hydrophobicity. It is likely that these conditions were not suitable for the formation of stable oligomers. In this case, although hydrogen bonds may be strengthened, the hydrophobic interactions are diminished [37, 38]. That is, the hydrophobicity of the environment might interfere with hydrophobic interactions which are necessary for

oligomer formation. This would explain why oligomers formed in non- halogenated alcohols are less stable. It may also be mentioned that the stability of protein Barstar oligomers generated in the presence of HFIP is higher than oligomer formed under heat or TFE [34].

\section{Conclusions}

At low $\mathrm{pH}, \mathrm{Apo-BCA}$ forms a molten and a pre-molten globule state. In contrast to the molten globule state, the pre-molten globule state converts to spherical oligomers 
with amyloid-like characteristics in the presence of alcohols. Protein oligomers have been shown to have pathogenic properties in the abnormal protein-deposit related diseases and studying their characteristics is of importance. Oligomers observed in the current study, and especially the stable species, may be of help related to this line of research.

\section{Acknowledgements}

This work was supported by grants from the research council of the University of Tehran and the Iranian National Science Foundation (INSF). The technical assistance kindly provided by Ms A. Ghasemi is gratefully acknowledged

\section{Materials and methods:}

\subsection{Materials}

Bovine carbonic anhydrase (BCA) (EC 4.2.1.1), Thioflavin T (ThT), and Congo red were purchased from Sigma (St Louis, MO, USA). 8-Anillino-1-naphthalene-sulfonic acid (ANS) was purchased from Fluka. Dipicolinic acid (DPA) and all salts and organic solvents (were of reagent grade and obtained from Merck (Darmstadt, Germany).

\subsection{Protein purification.}

Further purification of BCA was performed using a $\mathrm{p}$-(amino-methyl) benzene sulfonamide (p-AMBS) affinity column [39]. Purity of protein was confirmed by SDS- 
PAGE electrophoresis. Protein concentration was determined by the use of an extinction coefficient of $1.83 \mathrm{mg}^{-1} \mathrm{ml}^{-1}$ at $280 \mathrm{~nm}$. Protein was concentrated using centricon centrifugal filter devices (cut-off: $3 \mathrm{kD}$ ).

\subsection{Apo-BCA preparation and metal content analysis}

Protein solution was dissolved in $50 \mathrm{mM}$ sodium phosphate buffer $(\mathrm{pH} 8)$ and dialysed against the same buffer containing $100 \mathrm{mM}$ of dipicolinic acid (as chelator) for $48 \mathrm{~h}$ in order to remove the chelator, further dialysis was performed thrice against $10 \mathrm{Mm}$ Tris $(\mathrm{pH}$ 7.5) [40]. The obtained solution was centrifuged at $10000 \mathrm{~g}$ for $10 \mathrm{~min}$ to remove any potential aggregates. Protein concentration of the supernatant was determined by measuring absorbance at $280 \mathrm{~nm}$. Zinc content of apo-protein preparations was determined by ICP-OES analysis [41]. Over $92 \%$ of the metal was removed by using this method.

\subsection{Induction of amyloid-like structures}

Apo- BCA was incubated at a concentration of $133 \mu \mathrm{M}$ for $24 \mathrm{~h}$ in $50 \mathrm{mM}$ Glycine, $\mathrm{pH}$ $2.4,25^{\circ} \mathrm{C}$ in the presence of various concentrations of alcohols ranging from 0 to $60 \%$ (vol./vol.).

\subsection{ThT assay}

ThT assay was performed as reported previously [42]. Briefly, $10 \mu \mathrm{l}$ of BCA samples were added to $590 \mu \mathrm{l}$ of $25 \mu \mathrm{M}$ ThT solutions (from $2.5 \mathrm{mM}$ ThT stock solution in $25 \mathrm{mM}$ sodium phosphate, $\mathrm{pH}$ 6, passed through a $0.45 \mu$ filter paper), ThT emission intensity was then measured over time at $25{ }^{\circ} \mathrm{C}$ using a thermostat-equipped Perkin Elmer spectrofluorimeter. Fluorescence emission spectra were taken using 
excitation at $445 \mathrm{~nm}$ and emission at $\mathbf{4 8 5}$ was measured. The excitation and emission slit widths were set as 5 and $10 \mathrm{~nm}$, respectively.

\subsection{CD analysis}

Far-UV CD spectra were obtained by an Aviv 215 spectropolarimeter (Aviv Associates, Lakewood, NJ). A quartz cell with a $0.05 \mathrm{~mm}$ light path and protein concentration of $13.3 \mu \mathrm{M}$ at $25^{\circ} \mathrm{C}$ was used to record far-UV CD spectrum from 190 to $260 \mathrm{~nm}$ and light path which were $16 \mu \mathrm{M}$ and $10 \mathrm{~mm}$, respectively.

\subsection{Atomic force microscopy}

Apo-BCA was incubated at a concentration of $133 \mu \mathrm{M}$ for $24 \mathrm{~h}$ in $50 \mathrm{mM}$ Glycine, $\mathrm{pH}$ $2.425^{\circ} \mathrm{C}$ in the presence of various concentrations of alcohols. Ten-microliter aliquots of samples were diluted in deionized water down to a concentration of $1 \mu \mathrm{M}$. Diluted sample was immediately deposited on freshly cleaved mica and dried under a gentle nitrogen flux. Contact $A C$ mode atomic force microscopy (AFM) images were acquired in air using a Veeco microscope. Oligomers size was measured from the height in cross section of the topographic AFM images.

\subsection{Dynamic light scattering (DLS)}

DLS experiments were carried out using a Zeta Potential and Particle Size Analyzer (Brookhaven Instrument, Holtsville, NY 11742-1896 USA). Aliquots of incubated solutions at $16 \mu \mathrm{M}$ concentration were filtered through a $0.2 \mu \mathrm{m}$ syringe filter before 
measurements. A laser of $657 \mathrm{~nm}$ with a fixed detector angle of $90^{\circ}$ was used and DLS experiments were performed at least in triplicates.

\subsection{ANS binding assays}

Apo-BCA was incubated for $4 \mathrm{~h}$ at $25{ }^{\circ} \mathrm{C}$ in optimal concentration of different alcoholes as described previously for other proteins [43]. 50 $\mu$ l aliquots of the protein solutions were mixed with $450 \mu$ l of solutions containing $100 \mu \mathrm{M}$ ANS, in $25 \mathrm{mM}$ phosphate buffer, $\mathrm{pH} 6.5$, at $25^{\circ} \mathrm{C}$ (final concentration of protein was 13 $\mu M$ ). Fluorescence spectra were taken with the use of a thermostat-equipped PerkinElmer spectrofluorimeter, Excitation wavelength of $380 \mathrm{~nm}$ was used, and emission measured range was from 400 to $600 \mathrm{~nm}$. Excitation and emission slit widths were set at 5 and $10 \mathrm{~nm}$ respectively [44, 45].

\subsection{Stability study of apo-BCA oligomers}

Stability of amyloid-like oligomers was studied according to a previous reported [43]. Apo-BCA oligomers were first formed by incubating the protein in $50 \mathrm{mM}$ Glycine buffer, (pH 2.4), for $24 \mathrm{~h}$ at $25{ }^{\circ} \mathrm{C}$ in the presence of optimal concentrations of different alcohols. The samples were then diluted 4-fold into 50 $\mathrm{mM}$ sodium phosphate buffer, $\mathrm{pH} 7.0$ at $25^{\circ} \mathrm{C}$. The final $\mathrm{pH}$ after dilution was 7.0. After $1 \mathrm{~h}$ of incubation at $\mathrm{pH} 7.0$, and $25^{\circ} \mathrm{C}$, aliquots were withdrawn and ThT fluorescence intensity was recorded for $24 \mathrm{~h}$ as described above. 


\section{References}

[1] A. Jasanoff, A.R. Fersht, Biochemistry, 33 (1994) 2129-2135.

[2] W. Liu, J.M. Prausnitz, H.W. Blanch, Biomacromolecules, 5 (2004) 1818-1823.

[3] C.M. Dobson, Semin Cell Dev Biol, 15 (2004) 3-16.

[4] M. Stefani, Biochim Biophys Acta, 1739 (2004) 5-25.

[5] C. Frieden, Protein Sci, 16 (2007) 2334-2344.

[6] V.N. Uversky, A.L. Fink, Biochimica et Biophysica Acta (BBA)-Proteins and Proteomics, 1698 (2004) 131-153.

[7] Z.A. Oztug Durer, J.A. Cohlberg, P. Dinh, S. Padua, K. Ehrenclou, S. Downes, J.K. Tan, Y. Nakano, C.J. Bowman, J.L. Hoskins, C. Kwon, A.Z. Mason, J.A. Rodriguez, P.A. Doucette, B.F. Shaw, J.S. Valentine, PLoS One, 4 (2009) e5004.

[8] P. Wittung-Stafshede, Accounts of chemical research, 35 (2002) 201-208.

[9] W.R. Chegwidden, N.D. Carter, Introduction to the carbonic anhydrases, in: The Carbonic Anhydrases, Springer, 2000, pp. 13-28.

[10] A. Es-haghi, S. Shariatizi, A. Ebrahim-Habibi, M. Nemat-Gorgani, Biochimica et Biophysica Acta (BBA)-Proteins and Proteomics, 1824 (2012) 468-477.

[11] V.N. Uversky, O.B. Ptitsyn, Biochemistry, 33 (1994) 2782-2791.

[12] M.R. Nilsson, Methods, 34 (2004) 151-160.

[13] D. Dolgikh, L. Abaturov, I. Lebedev, I. Chirgadze, Doklady Akademii Nauk SSSR, 272 (1983) 1481.

[14] V.N. Uversky, J. Li, A.L. Fink, Journal of Biological Chemistry, 276 (2001) 10737-10744.

[15] M. Bouchard, J. Zurdo, E.J. Nettleton, C.M. Dobson, C.V. Robinson, Protein Sci, 9 (2000) 1960-1967.

[16] B. Ahmad, J. Winkelmann, B. Tiribilli, F. Chiti, Biochimica et Biophysica Acta (BBA)-Proteins and Proteomics, 1804 (2010) 223-234.

[17] K. Yamaguchi, H. Naiki, Y. Goto, J Mol Biol, 363 (2006) 279-288.

[18] S. Srisailam, T.K. Kumar, D. Rajalingam, K.M. Kathir, H.S. Sheu, F.J. Jan, P.C. Chao, C. Yu, J Biol Chem, 278 (2003) 17701-17709.

[19] M. Buck, Quarterly reviews of biophysics, 31 (1998) 297-355.

[20] K. Gast, A. Siemer, D. Zirwer, G. Damaschun, European Biophysics Journal, 30 (2001) 273-283.

[21] P. Gupta, S. Deep, Biochem Biophys Res Commun, 449 (2014) 126-131.

[22] N. Hirota, K. Mizuno, Y. Goto, Journal of molecular biology, 275 (1998) 365-378.

[23] R. Chitra, P.E. Smith, The Journal of Chemical Physics, 114 (2001) 426-435.

[24] N. Chaudhary, S. Singh, R. Nagaraj, Biopolymers, 90 (2008) 783-791.

[25] R. Rajan, P. Balaram, International journal of peptide and protein research, 48 (1996) 328-336.

[26] K. Yanagi, M. Ashizaki, H. Yagi, K. Sakurai, Y.-H. Lee, Y. Goto, Journal of Biological Chemistry, 286 (2011) 23959-23966.

[27] D.M. Hatters, L.J. Lawrence, G.J. Howlett, FEBS letters, 494 (2001) 220-224.

[28] D.-P. Hong, M. Hoshino, R. Kuboi, Y. Goto, Journal of the American Chemical Society, 121 (1999) 8427-8433.

[29] K. Yanagi, M. Ashizaki, H. Yagi, K. Sakurai, Y.H. Lee, Y. Goto, J Biol Chem, 286 23959-23966.

[30] M. Weijers, K. Broersen, P.A. Barneveld, M.A. Cohen Stuart, R.J. Hamer, H.H. De Jongh, R.W.

Visschers, Biomacromolecules, 9 (2008) 3165-3172.

[31] K. Yanagi, M. Ashizaki, H. Yagi, K. Sakurai, Y.H. Lee, Y. Goto, J Biol Chem, 286 (2011) 23959-23966.

[32] A. Abedini, D.P. Raleigh, Physical biology, 6 (2009) 015005.

[33] C.A. Hauser, R. Deng, A. Mishra, Y. Loo, U. Khoe, F. Zhuang, D.W. Cheong, A. Accardo, M.B. Sullivan, C. Riekel, Proceedings of the National Academy of Sciences, 108 (2011) 1361-1366.

[34] A. Sekhar, J.B. Udgaonkar, Biochemistry, 50 (2011) 805-819. 
[35] L.A. Munishkina, C. Phelan, V.N. Uversky, A.L. Fink, Biochemistry, 42 (2003) 2720-2730.

[36] M. Biancalana, S. Koide, Biochimica et Biophysica Acta (BBA)-Proteins and Proteomics, 1804 (2010) 1405-1412.

[37] D. Roccatano, G. Colombo, M. Fioroni, A.E. Mark, Proc Natl Acad Sci U S A, 99 (2002) 12179-12184.

[38] K. Gast, A. Siemer, D. Zirwer, G. Damaschun, Eur Biophys J, 30 (2001) 273-283.

[39] O. Ozensoy, O. Arslan, S.O. Sinan, Biochemistry (Moscow), 69 (2004) 216-219.

[40] J.B. Hunt, M.-J. Rhee, C.B. Storm, Analytical biochemistry, 79 (1977) 614-617.

[41] J. Otero-Romaní, A. Moreda-Piñeiro, P. Bermejo-Barrera, A. Martin-Esteban, Talanta, 79 (2009) 723 729.

[42] M.R. Nilsson, Methods, 34 (2004) 151-160.

[43] B. Ahmad, J. Winkelmann, B. Tiribilli, F. Chiti, Biochim Biophys Acta, 1804 (2010) 223-234.

[44] Z. Salemi, S. Hosseinkhani, B. Ranjbar, M. Nemat-Gorgani, J Biochem Mol Biol, 39 (2006) 636-641.

[45] D. Morshedi, A. Ebrahim-Habibi, A.A. Moosavi-Movahedi, M. Nemat-Gorgani, Biochim Biophys Acta, 1804 (2010) 714-722.

Table1: Height of oligomers formed in various alcohols. At least 20 oligomer samples ( N) were selected and their height was measured by WSxM software. SD stands for standard deviation. 


\begin{tabular}{|c|c|c|c|}
\hline alcohol & $\begin{array}{c}\text { Average height of } \\
\text { oligomer (nm) }\end{array}$ & S.D. & $\mathrm{N}$ \\
\hline HFIP & 2.02 & 0.49 & 41 \\
\hline \multirow{3}{*}{ TFE } & 2.92 & 0.60 & 26 \\
\hline & 7.23 & 1.01 & 26 \\
\hline & 11.10 & 1.19 & 26 \\
\hline \multirow{2}{*}{ Methanol } & 8.59 & 1.09 & 22 \\
\hline & 12.93 & 1.77 & 32 \\
\hline Ethanol & 5.23 & 0.70 & 41 \\
\hline \multirow[t]{2}{*}{ Propanol } & 7.46 & 0.66 & 38 \\
\hline & 10.28 & 1.10 & 38 \\
\hline
\end{tabular}

\section{Legend to Figures}

Figure 1: The effect of various alcohols in the formation of amyloid -like aggregate by apo- BCA in the Glycine buffer $\mathrm{pH} 2.4$ after $24 \mathrm{~h}$ of incubation at $25^{\circ} \mathrm{C}$. Maximum ThT 
emission at $485 \mathrm{~nm}$ and $215 \mathrm{~nm}$ ellipticity is plotted against the concentration of alcohols. Optimal concentration for formation of amyloid-like structures are as follows: methanol $35 \%(\mathrm{v} / \mathrm{v})$, ethanol, $45 \%(\mathrm{v} / \mathrm{v})$; propanol, $60 \%(\mathrm{v} / \mathrm{v})$; TFE, $12 \%(\mathrm{v} / \mathrm{v})$; and HFIP5 \%(v/v).

Figure 2: AFM images of amyloid- like aggregate in various alcohols. Oligomers were prepared in (a) $5 \%(\mathrm{v} / \mathrm{v})$ HFIP, (b) $12 \%$ (v/v) TFE, $35 \%(\mathrm{v} / \mathrm{v})$ Methanol, 45\%(v/v) Ethanol and 60\% (v/v) propanol. $50 \mathrm{mM}$ Glycine buffer was used and the protein (133 $\mu \mathrm{M}$ ) was incubated at $25^{\circ} \mathrm{C}$ for 24 hours.

Figure 3: Apparent hydrodynamic diameter of apo-BCA oligomers formed in various alcohols after $24 \mathrm{~h}$ of incubation at $50 \mathrm{mM}$ Glycine buffer $\mathrm{pH} 2.4$ and $25^{\circ} \mathrm{C}$ obtained by DLS. Solution containing protein was diluted 3 times in buffer Glycine so that the protein concentration was $16 \mu \mathrm{M}$.

Figure 4: Kinetics of amyloid-like aggregates formation of apo-BCA (133 $\mu \mathrm{M}$ in Glycine buffer at $25^{\circ} \mathrm{C}$ ) and in the presence of 12\% TFE. (a) in time 0 (1), 1 minute (2), 15 minutes (3), 30 minutes(4), 1 hour (5), 2 hours (6), 3 hours (7) and 4 hours (8).

Figure 5: ANS emission changes of apo-BCA incubated in various alcohol concentrations for 24 hours at $25^{\circ} \mathrm{C}$ and $50 \mathrm{mM}$ Glycine buffer pH2.4. Intensity of emission at $482 \mathrm{~nm}$ is plotted against the concentration of alcohol. 
Figure 6: Stability of Oligomers formed in various alcohols: HFIP 5\% (•), TFE12\% (०), methanol $35 \%(\boldsymbol{\nabla})$, ethanol $45 \%(\boldsymbol{-})$ and propanol $60 \%(\Delta)$. After $24 \mathrm{~h}$, the protein solution was diluted 10 times in Tris buffer $(\mathrm{pH} 7.5)$ and ThT emission was measured against time.

Figure 7: Evaluation of hydrophobicity of alcohol solutions that led to apo-BCA aggregation. TFE 12\% (•), HFIP 5\% (०), methanol 35\% ( $\boldsymbol{\nabla})$, ethanol $45 \%(\Delta)$ and propanol $60 \%(\boldsymbol{\square})$ 

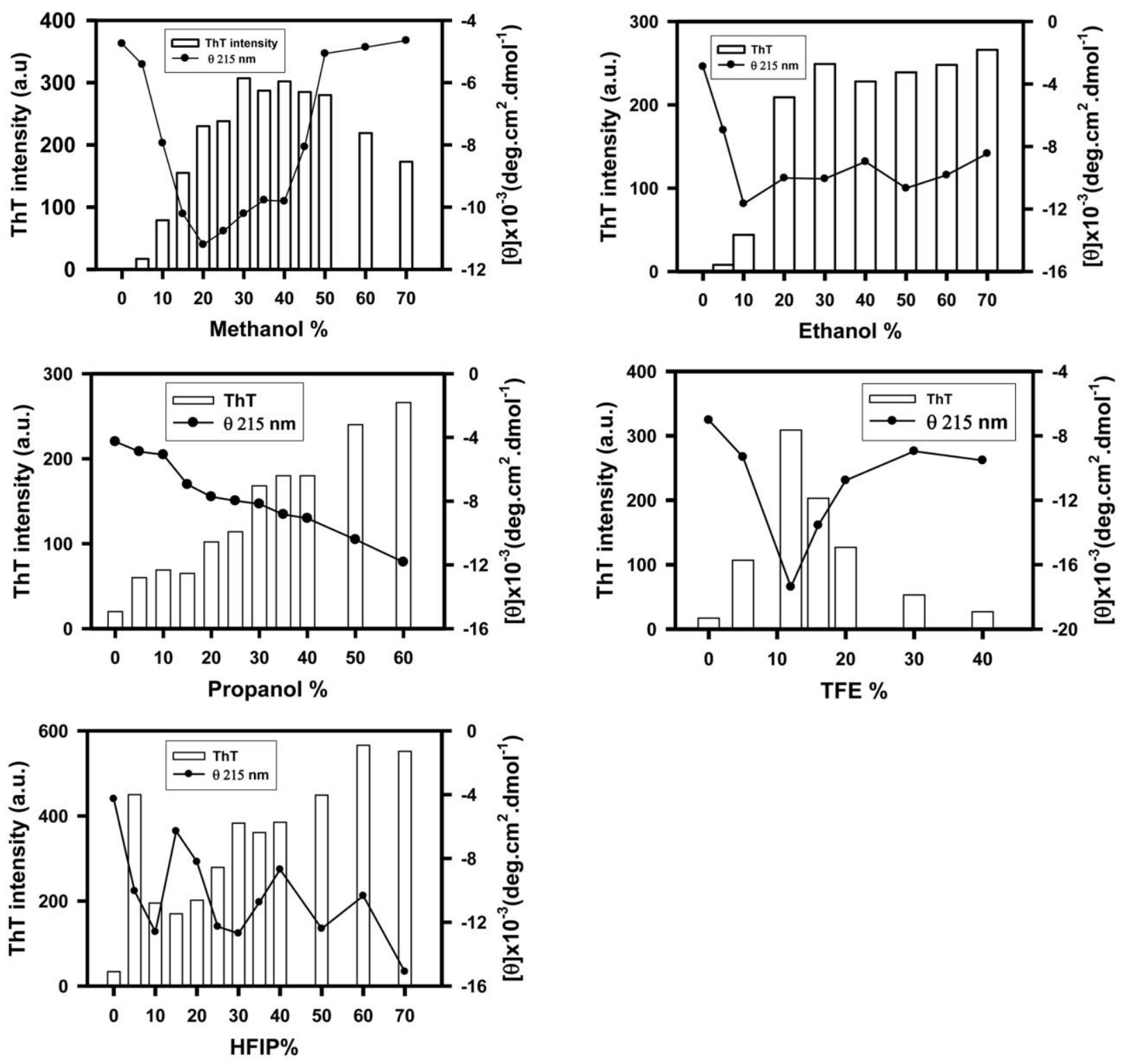


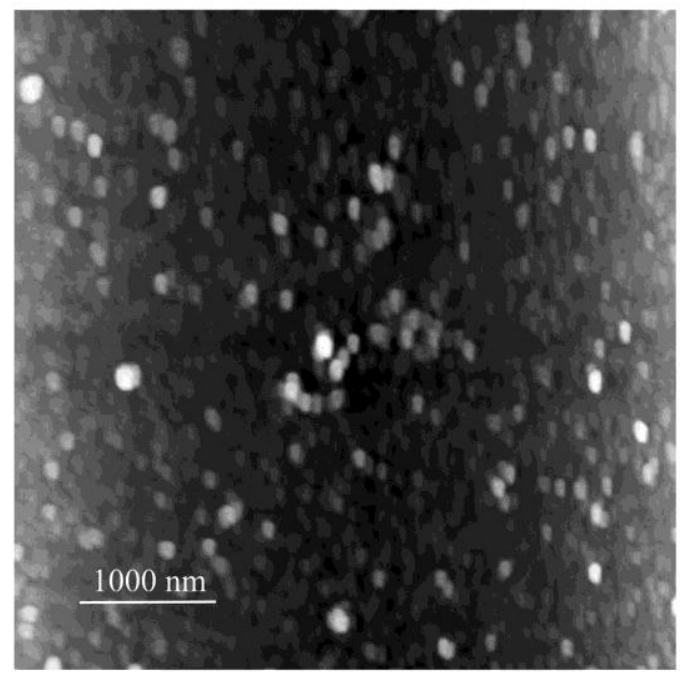

Methanol 35\%

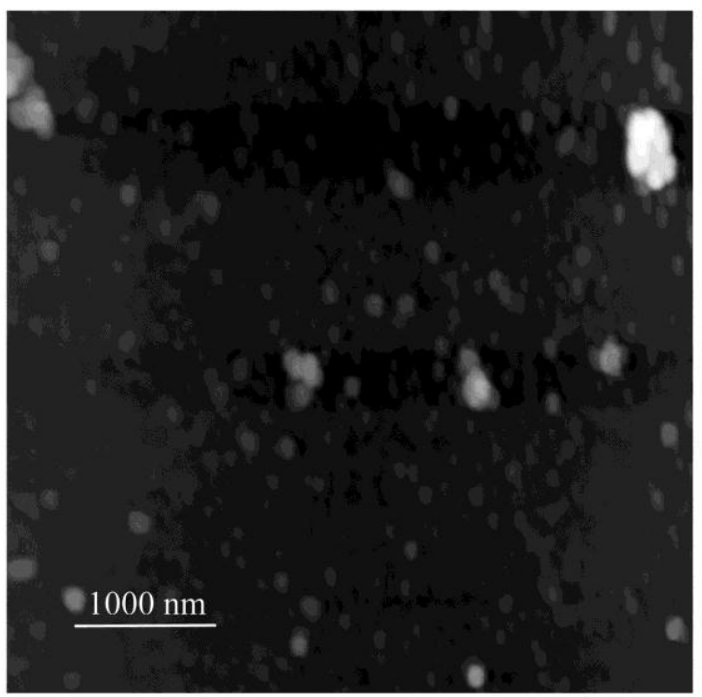

Propanol 60\%

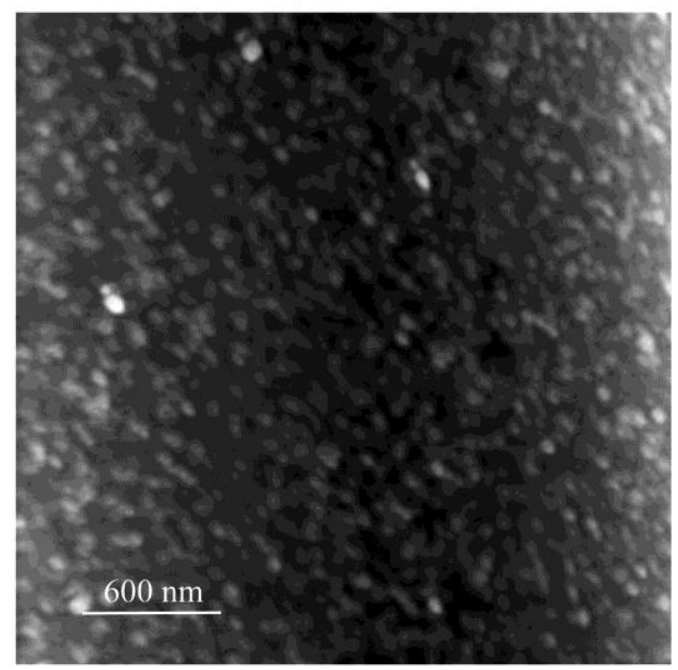

HFIP 5\%

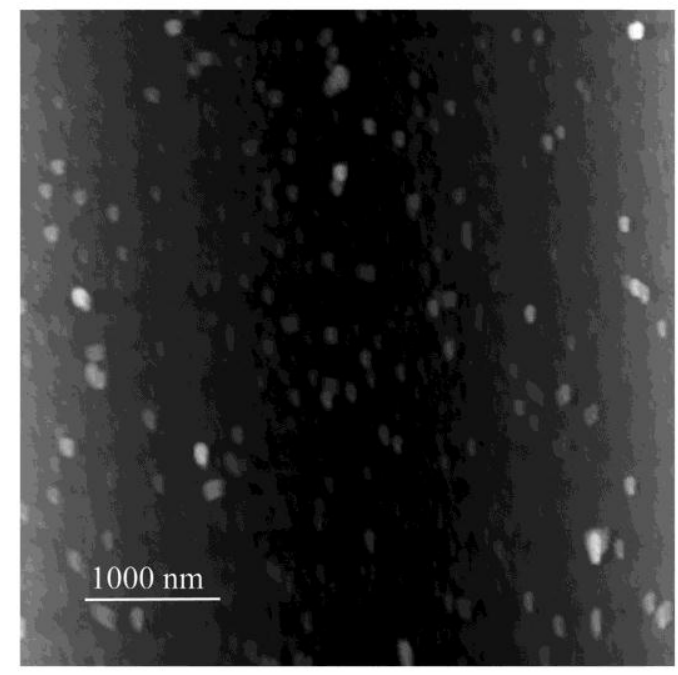

Ethanol 45\%

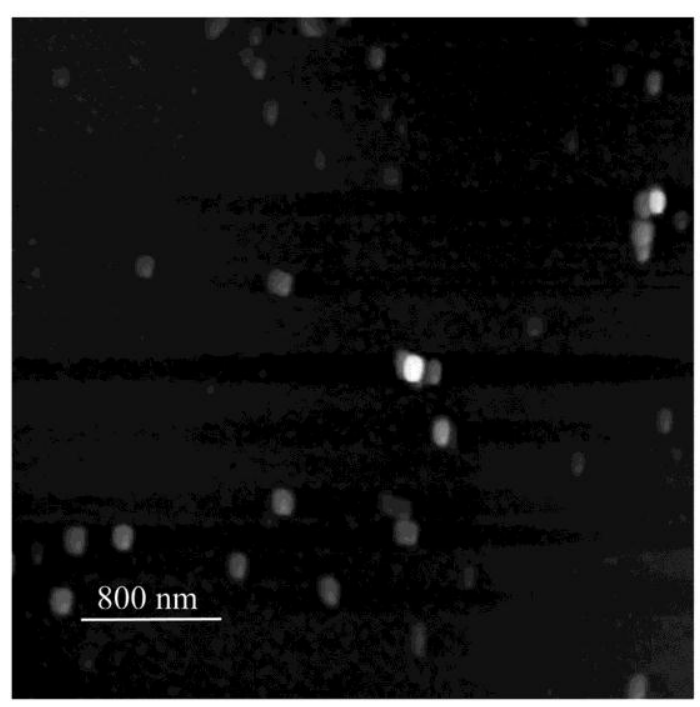

TFE 12\% 


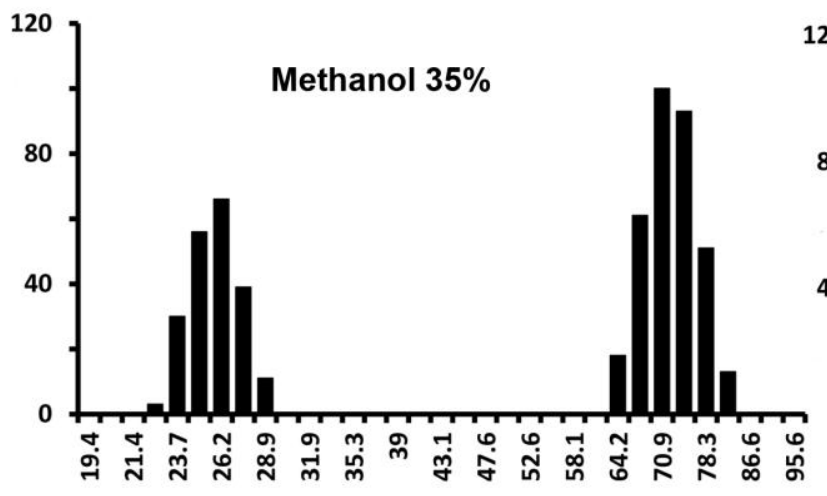

Size $(\mathrm{nm})$
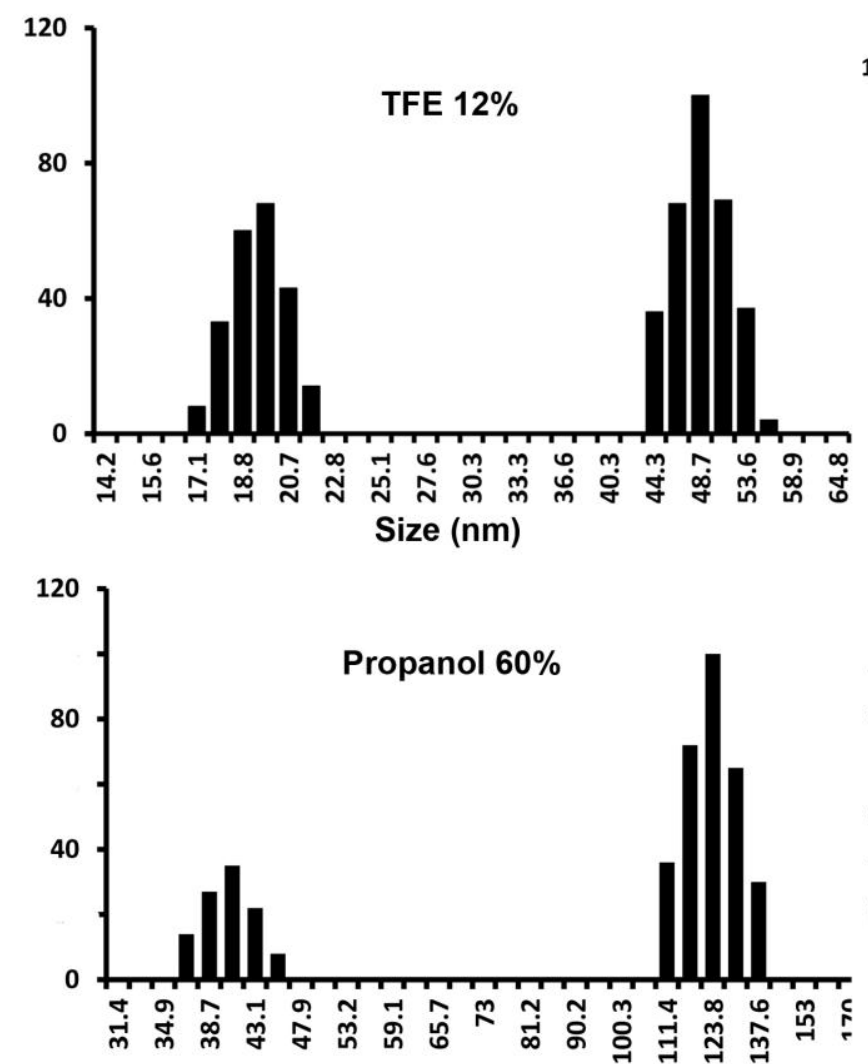

Size (nm)

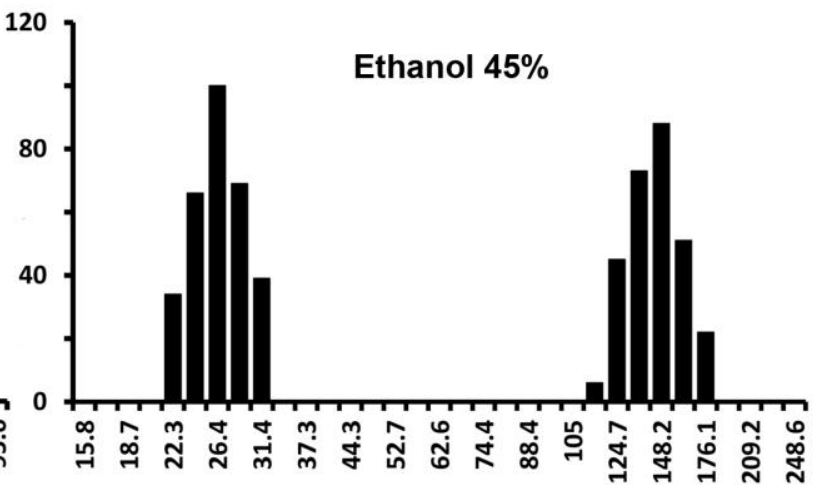

Size (nm)
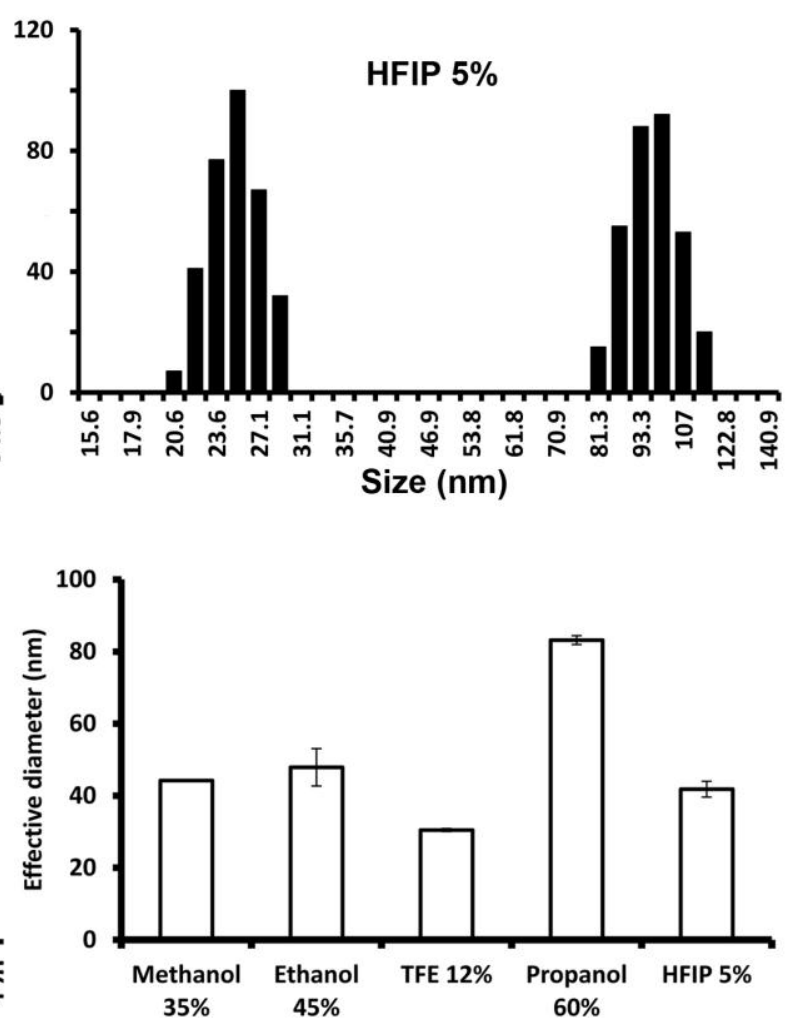


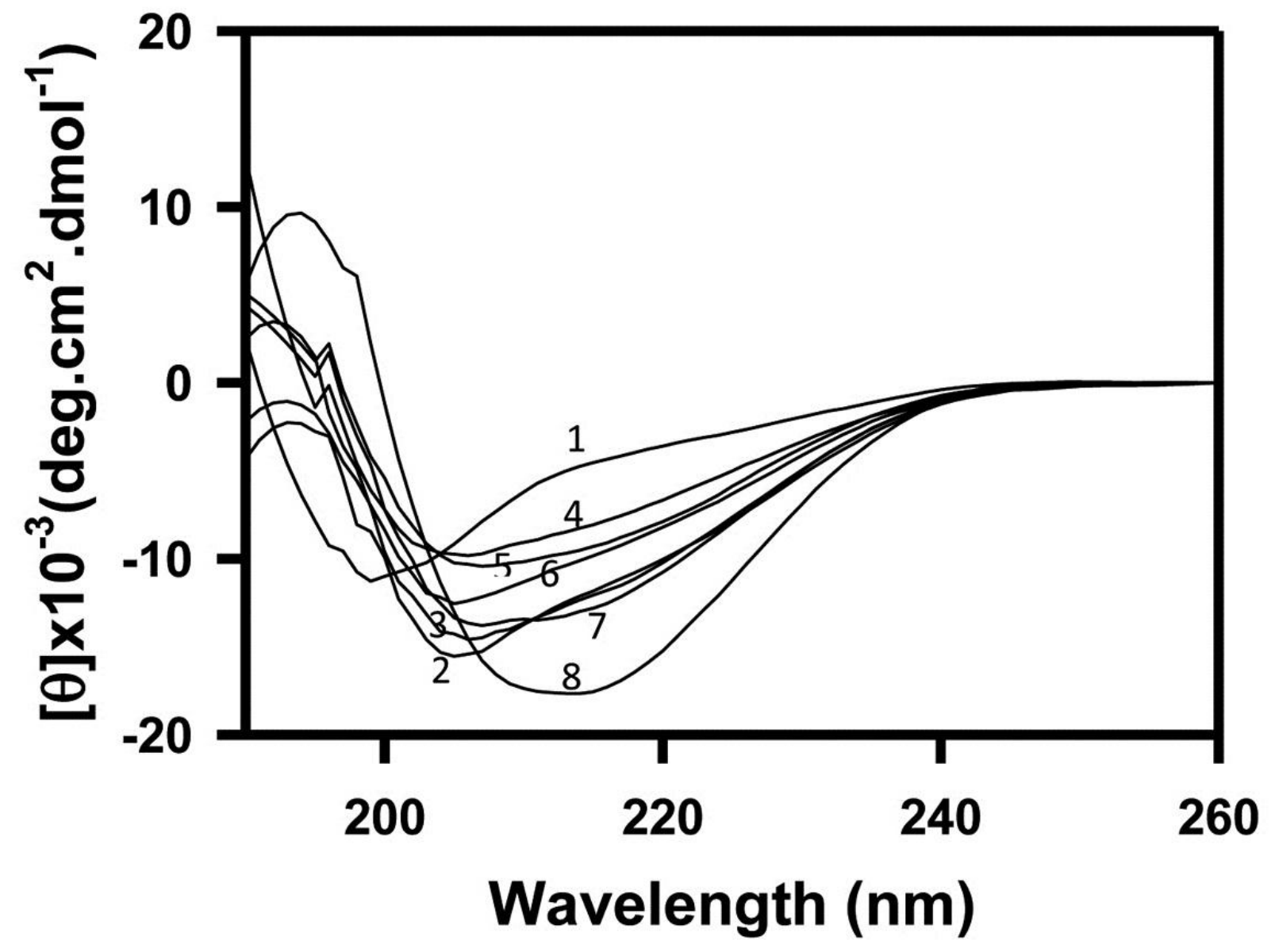



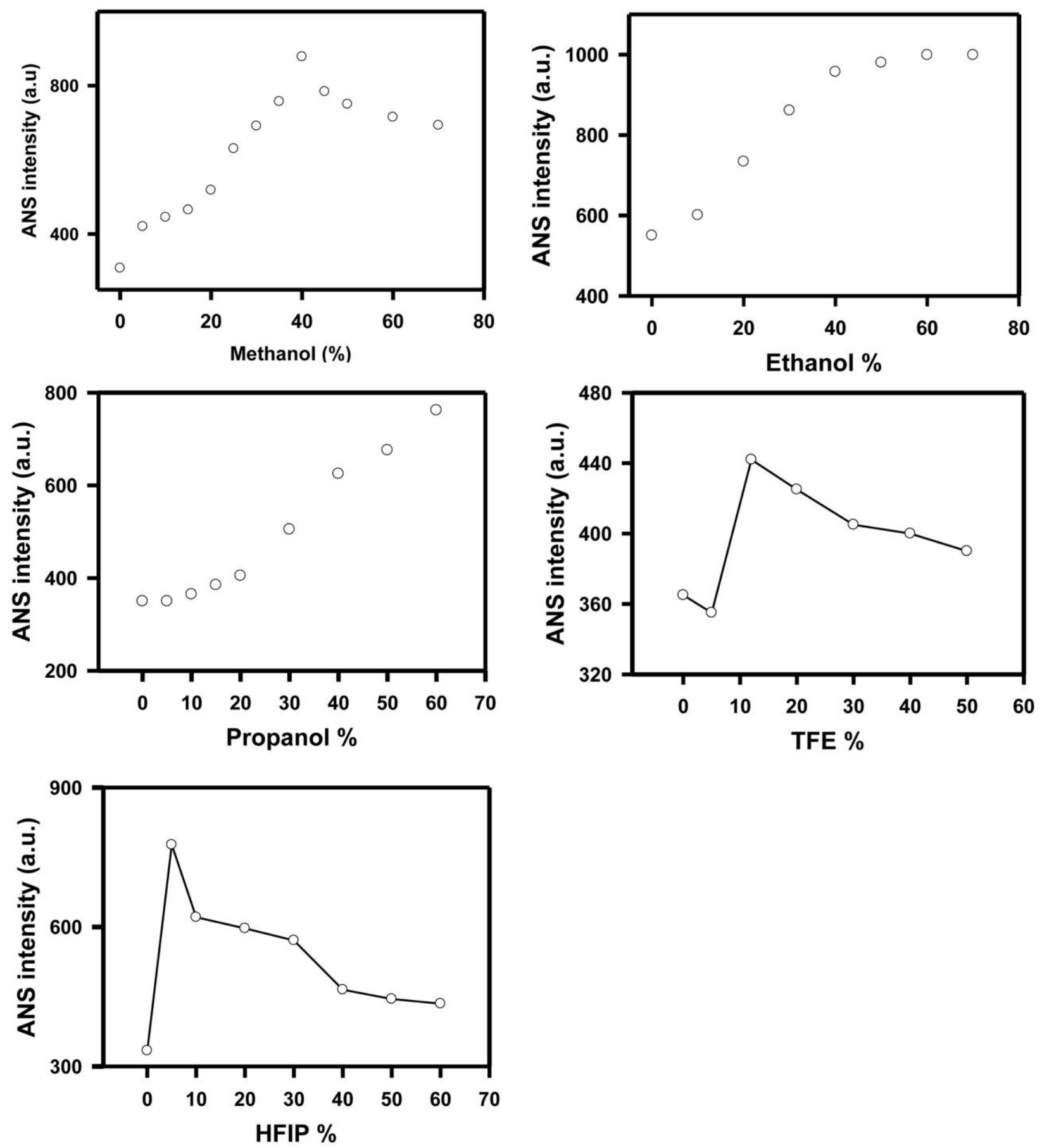


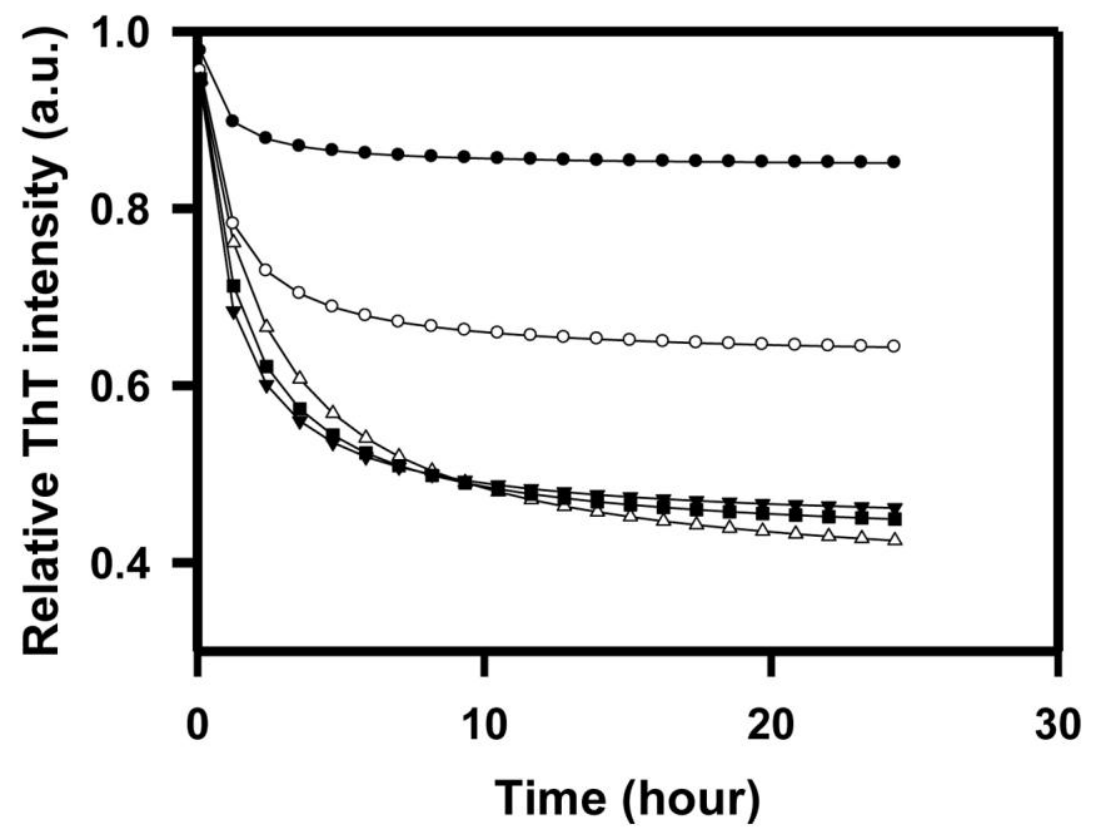




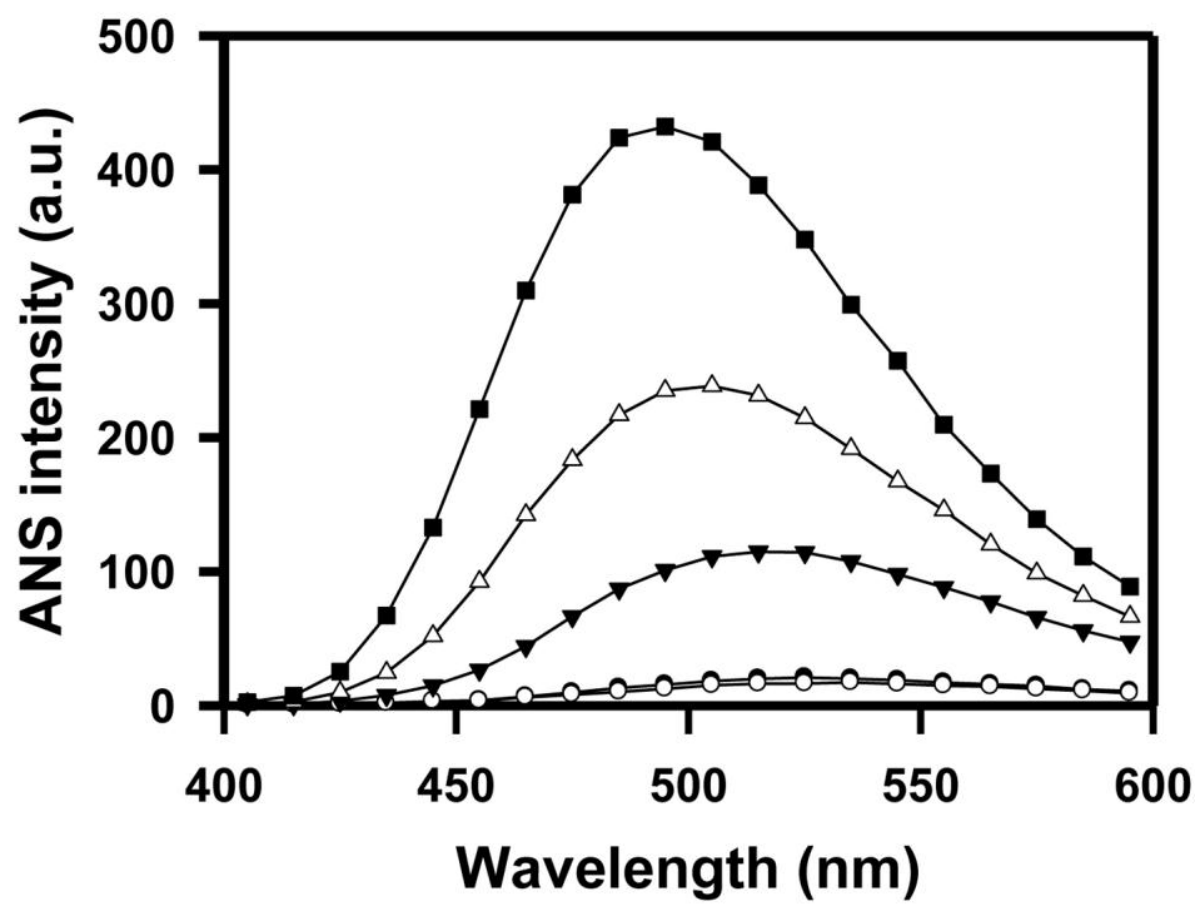




\begin{tabular}{|c|c|c|c|}
\hline alcohol & $\begin{array}{c}\text { Average height of } \\
\text { oligomer }\end{array}$ & S.D. & $\mathrm{N}$ \\
\hline HFIP & 2.022903 & 0.495243 & 41 \\
\hline \multirow{3}{*}{ TFE } & 2.9275 & 0.600349 & 26 \\
\cline { 2 - 4 } & 7.233125 & 1.01006 & 26 \\
\cline { 2 - 4 } & 11.10063 & 1.195849 & 26 \\
\hline \multirow{3}{*}{ Methanol } & 8.596 & 1.092943 & 22 \\
\cline { 2 - 4 } & 12.9375 & 1.77799 & 32 \\
\hline Ethanol & 5.230476 & 0.70533 & 41 \\
\hline Propanol & 7.468 & 0.66432 & 38 \\
\cline { 2 - 4 } & 10.28401 & 1.104597 & 38 \\
\hline
\end{tabular}

